\title{
Endoscopic management of rectal neuroendocrine tumours. How to avoid a mistake and what to do when one is made?
}

\author{
Krzysztof Dąbkowski ${ }^{\circledR}{ }^{1}$, Marek Szczepkowski², Beata Kos-Kudła ${ }^{3}$, Teresa Starzyńska' \\ ${ }^{1}$ Department of Gastroenterology, Pomeranian Medical University, Szczecin, Poland \\ ${ }^{2}$ Clinical Department of Colorectal, General, and Oncological Surgery, Centre of Postgraduate Medical Education, Warsaw, Poland \\ ${ }^{3}$ Department of Endocrinology and Neuroendocrine Tumours, Department of Pathophysiology and Endocrinology, Medical \\ University of Silesia, Katowice, Poland
}

\begin{abstract}
Rectal neuroendocrine tumours are subepithelial lesions that are potentially malignant. Although the biology of these lesions has become increasingly understood and their management has been established, the endoscopic management of these tumours remains controversial. Recent studies demonstrated that compliance with guidelines is poor, and the majority of rectal neuroendocrine tumours are removed by an improper method, making management more complex and putting patients at risk of metastatic spread. Thus, there is a need to educate physicians who care for patients with these disorders. Our review has some tips and pointers for preventing mistakes in primary treatment and salvage therapy after polypectomy. (Endokrynol Pol 2020; 71 (4): 343-349)
\end{abstract}

Key words: rectal neuroendocrine tumours; endoscopic ultrasound; endoscopic submucosal dissection; transanal endoscopic microsurgery

\section{Introduction}

Rectal neuroendocrine neoplasms (rNENs) are subepithelial lesions that are diagnosed with increasing frequency. They are typically small tumours with low malignant potential, but risk of metastasis [1], which depends inter alia on the tumour mitotic index, vessel infiltration, and size [1]. The endoscopic management of rNENs has been established, but controversies remain [1-5]. Taking into account their subepithelial origin and malignant potential, they should be removed either by endoscopic mucosal resection (EMR), endoscopic submucosal dissection (ESD), transanal endoscopic microsurgery (TEM), or surgery [5]. The removal of these lesions with a snare or biopsy forceps results in an unacceptably high rate of incomplete resections [6, 7]. The natural history of rNENs shows that using an improper method to remove the tumour puts patients at risk of metastases development, resulting in repeated follow-up radiologic, endoscopic examinations and the need for salvage therapy $[8,9]$.

Recent studies have shown that the majority of lesions are removed by an improper method, even when typical endoscopic features are present, and diagnoses are made retrospectively based on histopathological assessment $[9,10]$. Thus, there is still a need to educate physicians caring for patients with rNENs, so that accurate diagnoses are made before the "simple" polypectomy (mistake) is done, and to broaden the knowledge of the management after ineffective treatment [11]. Herein, we review the key points of endoscopic management, from diagnosis to treatment.

\section{Clinical and endoscopic characteristics of rectal neuroendocrine tumours: diagnosis, management, and avoiding mistakes}

Rectal NENs constitute about $1 \%$ of rectal neoplastic lesions, and they are often accidental findings in colonoscopy [5]. Symptoms including changes in bowel habits, rectal bleeding, and abdominal pain, which are present in $50 \%$ of individuals; however, they can be attributed more to other underlying diseases (e.g. haemorrhoids, irritable bowel disease) than to the presence of the tumour itself [5]. Moreover, hormonal activity and symptoms of carcinoid syndrome, in contrast to small intestinal neuroendocrine tumours (NETs), are rare [1].

Rectal NETs are usually small $(<10 \mathrm{~mm}$ in diameter) single lesions located 5-10 cm from the dental line [2]. Typically, they manifest as regular lesions with yellow or white reflexion and smooth intact covering mucosa 


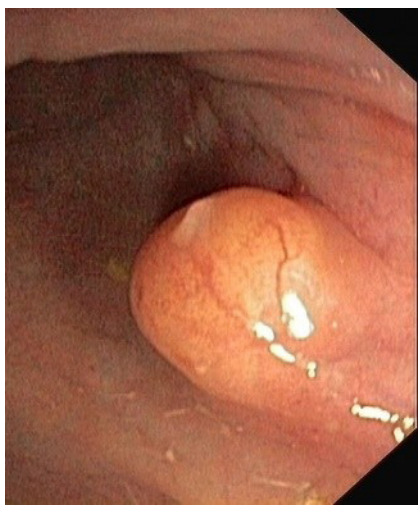

Figure 1. Typical rectal neuroendocrine tumour with yellow reflexion

(Fig. 1) [1, 2]. Atypical manifestations include lesions with central depression/ulceration/scar (Fig. 2), and lesions with central hyperaemia or flat seating small polyps that are hard to distinguish from hyperplastic polyps. The key issue in the initial management of these lesions is to suspect rectal NEN based on macroscopic features before mistakenly performing routine snare polypectomy. A retrospective analysis by Lee et al. [11] showed that it was possible to suspect a NET by macroscopic appearance, on endoscopy, in $95.9 \%$ of cases (94/98 lesions) [12]. These tumours are also described as hard and movable, and some authors suggested checking these features with a biopsy forceps as a helpful diagnostic tool [12].

We postulate that in cases of tumours with typical morphology, the reason why rNENs are removed with a polypectomy is either routine or poor compliance with management guidelines. In a minority of cases, rectal NENs present as small lesions, just slightly protruding from the mucosa, making them hard to distinguish from other polypoid lesions (they resemble hyperplastic polyps), and they are routinely removed with biopsy forceps or a snare. An outstanding question is whether any tools are available that allow physicians to avoid a mistake in cases of such small lesions.

Since Kudo's pit pattern and endoscopic classifications (e.g. Narrow-band Imaging International Colorectal Endoscopic [NICE] classification) for colorectal neoplasms were presented with the use of video chromoendoscopy — narrow-band imaging (NBI) - we are able to predict the histopathology of epithelial lesions [13]. In the NICE classification colour for lesions, surface (pit pattern) and vessel patterns are assessed to differentiate benign hyperplastic polyps from adenoma, and adenoma from cancer. According to the meta-analysis by McGill et al., the differential diagnosis of neoplastic and non-neoplastic polyps with the use of NBI can be made with $91 \%$ specificity and $83 \%$ sensitivity [14]. To

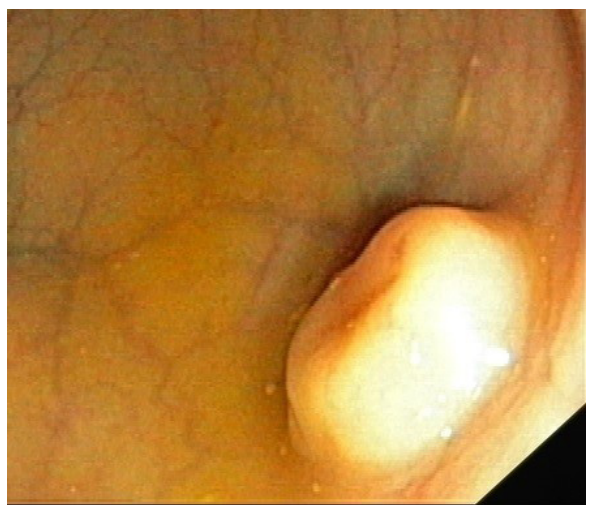

Figure 2. Subepithelial lesion with central depression

the best of our knowledge, only a few studies (mainly related to gastric lesions) and case reports have assessed NETs with NBI $[15,16]$. In the study by Lahner et al. all gastric type I NETs showed an abnormal surface pattern (tubulovillous or irregular), but with no specific features that distinguished them from other lesions [15]. In the case report by Lin et al., round pits larger than those seen in hyperplastic polyps surrounded by honeycomb brown microvessels were typical features of rNEN [16]. Taking into account the fact that the basis for endoscopic diagnosis is shifting from histopathology to advanced methods of imaging, the use of NBI and other methods of advanced imaging may be an interesting area of research, and hopefully will be a solution for characterising small rectal neuroendocrine polyps before they are removed by polypectomy.

Another area of controversy is the issue of taking a biopsy on initial endoscopy. We believe that routine biopsies from subepithelial lesions that look typical should be avoided, which would not significantly change the management strategy (EMR/ESD/TEM/surgery, preceded by endoscopic ultrasound [EUS]). Biopsy should only be considered in doubtful cases (atypical features) and in tumours that are more than $2 \mathrm{~cm}$ in size (according to the guidelines, these patients should be referred to surgery). The advantage of taking biopsies is the significantly high percentage of positive histopathological results compared to other subepithelial lesions, whereas the disadvantage is that it can lead to fibrosis and blur the tumour borders, making further endoscopic treatment more complicated from a technical viewpoint $[1,12]$. In the study by Lee et al. biopsy of rNENs on initial endoscopy was the only factor that was significantly related to the risk of incomplete tumour resection [12]. The authors underlined not only the aspect of uncertain tumour borders, which can lead to the problems with snaring and targeting the lesion, but also of preceding biopsy-related fibrosis, which can disturb the ESD or EMR [12]. 
The endoscopic treatment of lesions more than $5 \mathrm{~mm}$ in size should be preceded by other modalities. An endoscopic ultrasound, according to European Neuroendocrine Tumour Society (ENETS) guidelines, is indicated for lesions more than $5 \mathrm{~mm}$ in size, to identify muscular layer invasion and the presence of enlarged mesorectal lymph nodes [4, 5]. Studies have shown high concordance, reaching more than $90 \%$ (even $100 \%$ in the study by Ishii et al.) between the assessment of depth of invasion in EUS and postoperative histopathology $[17,18]$. This high accuracy allows for treatment planning (i.e. involvement of the muscular layer shifts treatment from ESD to TEM or surgery when surgery for enlarged lymph nodes is indicated). Rectal NENs in EUS typically present as hypoechoic, homogenous lesions derived from the submucosal layer. Some recent studies show low potential of malignancy and indolent behaviour of small rNENs [19-22], suggesting that EUS may not be essential before endoscopic treatment of rNENs $<10 \mathrm{~mm}$ in size $[19,21]$. This approach that shifts the indications for EUS (from 5 to $10 \mathrm{~mm}$ ), taking into account earlier observations showing metastatic potential of well-differentiated and small rNENs, remains, in our opinion, controversial [23].

The recommended methods of treatment are either EMR, ESD, TEM, or surgery, depending on tumour size and the presence of unfavourable features such as advanced histology (G2, G3), lymphangio invasion, infiltration of muscular layer, lymph nodes, and distant metastases. It should be underlined that the indications for endoscopic and surgical treatment proposed by different author guidelines differ slightly, as presented in Table 1.

Various endoscopic methods have been proposed as effective and safe for the treatment of rectal NENs, but an important issue is that of which method should be offered to patients. When making decisions the percentage of $\mathrm{R} 0$ resections, complications and the presence of muscle layer infiltration, and enlargement of lymph nodes in EUS should be taken into account. Studies have shown that the $\mathrm{R} 0$ resection rate is obtained more commonly with TEM (97.6-100\%) than with ESD (81.1-100\%) and EMR (47.8-80\%) (Tab. 2). The respectively low $\mathrm{R} 0$ resection rate is the reason why EMR is generally recommended for small $(<10 \mathrm{~mm})$ lesions, and when used, modified methods (cap or ligation band EMR) of resection should be applied [5]. The meta-analysis by Zhou et al. comparing ESD and EMR for the treatment of rNENs demonstrated higher efficacy of ESD in terms of complete resection rate, with no significant differences between ESD and modified EMR [24]. There was also no statistically significant difference in complication risk; bleeding and perforation occurred in similar numbers in both groups of patients (6/209 in the ESD group and 6/418 in the EMR group) [24].

The percentage of reported complications of $\mathrm{rN}$ ENs treatment from ESD (0-9\%) is slightly lower than that in patients treated with TEM (2.6-13\%) (Tab. 1). In both methods, the majority of adverse events can be treated endoscopically or conservatively with no need for open surgical intervention. The advantage of TEM (compared to ESD), apart from the higher $\mathrm{R} 0$ resection rate, is that it can be used as a salvage treatment after non-radical therapy (after polypectomy and EMR as well as ESD), also allowing for sampling of perirectal lymph nodes. The disadvantages are the aforementioned complications, invasiveness of the procedure, and the need for anaesthesia and an operating room [25].

Recently, a new method of endoscopic treatment for colorectal tumours was presented, with the use of an endoscopic full-thickness resection device (FTRD) $[26,27]$. The study by Meyer et al. on 40 patients with rectal NENs showed not only the feasibility (median time, $18.5 \mathrm{~min}$ ) and safety (no major adverse events), but also the effectiveness of this method (R0 resection rate in 95\%) [26]. Moreover, in all reported case reports of rNEN, FTR showed its effectiveness and safety, both for the treatment of primary rectal NEN and as a salvage therapy after polypectomy [28-30]. Thus, FTR is a promising alternative to the aforementioned methods; however, comparative studies in larger groups of patients are needed to confirm its safety and efficacy.

We believe that the treatment method should be discussed with the patient, taking into account the aforementioned issues ( $\mathrm{R} 0$ resection rate, complications, invasiveness), the EUS results, and the experience of the centre. The data comparing methods used for the treatment of rectal NENs, including R0 resections and complications, are presented in Table 2.

\section{Management after simple polypectomy (what to do when a mistake is made)}

The ENETS guidelines recommend that all rectal NENs be removed with EMR/ESD/TEM or surgery [1, $4,5]$. This statement is based on the assumption that the diagnosis is made on endoscopy, and then the patient is referred for treatment, preceded by EUS. Unfortunately, this scenario is far from what occurs in real life, and in many cases, the neuroendocrine origin of the lesion is not suspected on endoscopy and the diagnosis is made retrospectively by a pathologist [10]. In the study by Fine $C$ et al. on a large group of 329 patients with small rNEN the suspicion of rNEN on endoscopy was made only in $18 \%$ of cases; despite 
Table 1. Indications for surgical and endoscopic treatment of rectal neuroendocrine neoplasms (rNENs) according to the guidelines

\begin{tabular}{|c|c|}
\hline Guideline & Recommended treatment \\
\hline ENETS 2012 [4] & $\begin{array}{l}\text { Surgery: } \\
\text { - }>2 \mathrm{~cm} \\
\text { - } 1-2 \mathrm{~cm} \text { with muscularis invasion, nodal positive, G2 T3, T4, G3 } \\
\text { TEM: } \\
\text { - }<1 \mathrm{~cm} \text { with muscularis invasion, G2, G3 } \\
\text { - } 1-2 \mathrm{~cm} \text { without muscularis invasion, nodal negative, G2, T1-T2 } \\
\text { - Endoscopy (ESD, EMR < } 10 \mathrm{~mm} \text { ): } \\
\text { - }<1 \mathrm{~cm} \text { without muscularis invasion, G1, G2 } \\
\text { - } 1-2 \mathrm{~cm} \text { without muscularis invasion } \mathrm{G} 1\end{array}$ \\
\hline NCCN 2019 [37] & $\begin{array}{l}\text { Surgery } \\
\text { - T2-T4 }>2 \mathrm{~cm} \\
\text { - } 1-2 \mathrm{~cm} \text { with muscularis propria invasion node positive } \\
\text { TEM or endoscopy: } \\
\text { - } \leq 2 \mathrm{~cm} \text { without muscularis invasion, node negative } \\
\text { - Endoscopic resection (method not specified): } \\
\text { - }<1 \mathrm{~cm}\end{array}$ \\
\hline NANETS 2010 [38] & $\begin{array}{l}\text { Surgery } \\
->2 \mathrm{~cm} \\
\text { - } 1-2 \text { with muscularis invasion, nodal positive } \\
\text { TEM: } \\
\text { - } 1-2 \mathrm{~cm} \text { without muscularis invasion, nodal negative } \\
\text { - consider in T2 tumours, when lymph node metastases are excluded } \\
\text { - Endoscopic resection (method not specified) } \\
\text { - }<1 \mathrm{~cm} \text { without muscularis invasion } \\
\text { - consider in tumours }<1-2 \mathrm{~cm} \text { confined to the mucosa/submucosa (T1) }\end{array}$ \\
\hline $\begin{array}{l}\text { Polish Network of Neuroendocrine } \\
\text { Tumours } 2017 \text { [1] }\end{array}$ & $\begin{array}{l}\text { Surgery } \\
->2 \mathrm{~cm} \\
-1-2 \mathrm{~cm} \text { with risk factors (TEM in individual cases) } \\
\text { Endoscopic resection (ESD): } \\
-<1 \mathrm{~cm} \\
-1-2 \mathrm{~cm} \text { without risk factors }\end{array}$ \\
\hline
\end{tabular}

ENETS - European Neuroendocrine Tumour Society; NANETS — North American Neuroendocrine Tumour Society; NCCN — National Comprehensive Cancer Network; TEM — transanal endoscopic microsurgery; ESD — endoscopic submucosal dissection; EMR — endoscopic mucosal resection

T1 — tumor invades the lamina propria or submucosa; T2 — tumour invades the muscular layer or is $\geq 2 \mathrm{~cm}$ in size; T3 — into subserosal tissue; T4 — invades serosa and/or adjacent organs - American Joint Committee on Cancer (AJCC) $8^{\text {th }}$ edition [39]

this, one third of those that were correctly recognised were removed by polypectomy [10]. Polypectomy of rectal NENs leads to an unacceptably high incomplete resection rate $(69.1-83 \%)$ and the risk of a presence of remnant residual tumour $[6,7,31,32]$. Endoscopic or surgical therapy after non-curative treatment is termed salvage therapy. It is based on performing more advanced treatment than the prior procedure (finding and removing the scar or remnant tumour with ESD or TEM) or removing the rectum and mesorectal lymph nodes with surgery. This adjunct treatment, the same as in primary excision, should be preceded by EUS to look for the remnant tumour and the presence of lymph node metastases.

The perception of salvage therapy has evolved from views that small tumours $(<1 \mathrm{~cm})$ with typical features can be removed with snare polypectomy, and in cases of incomplete resection, adjunct therapy is recommended $[1,17]$. This statement has been justified by the presence of a high percentage of residual tumours in patients who undergo salvage therapy, the risk of metastatic spread related to the natural biology of rectal NENs, 
Table 2. Data comparing $R 0$ resection rates and complications after endoscopic mucosal resection (EMR), endoscopic submucosal dissection (ESD), and transanal endoscopic microsurgery (TEM)

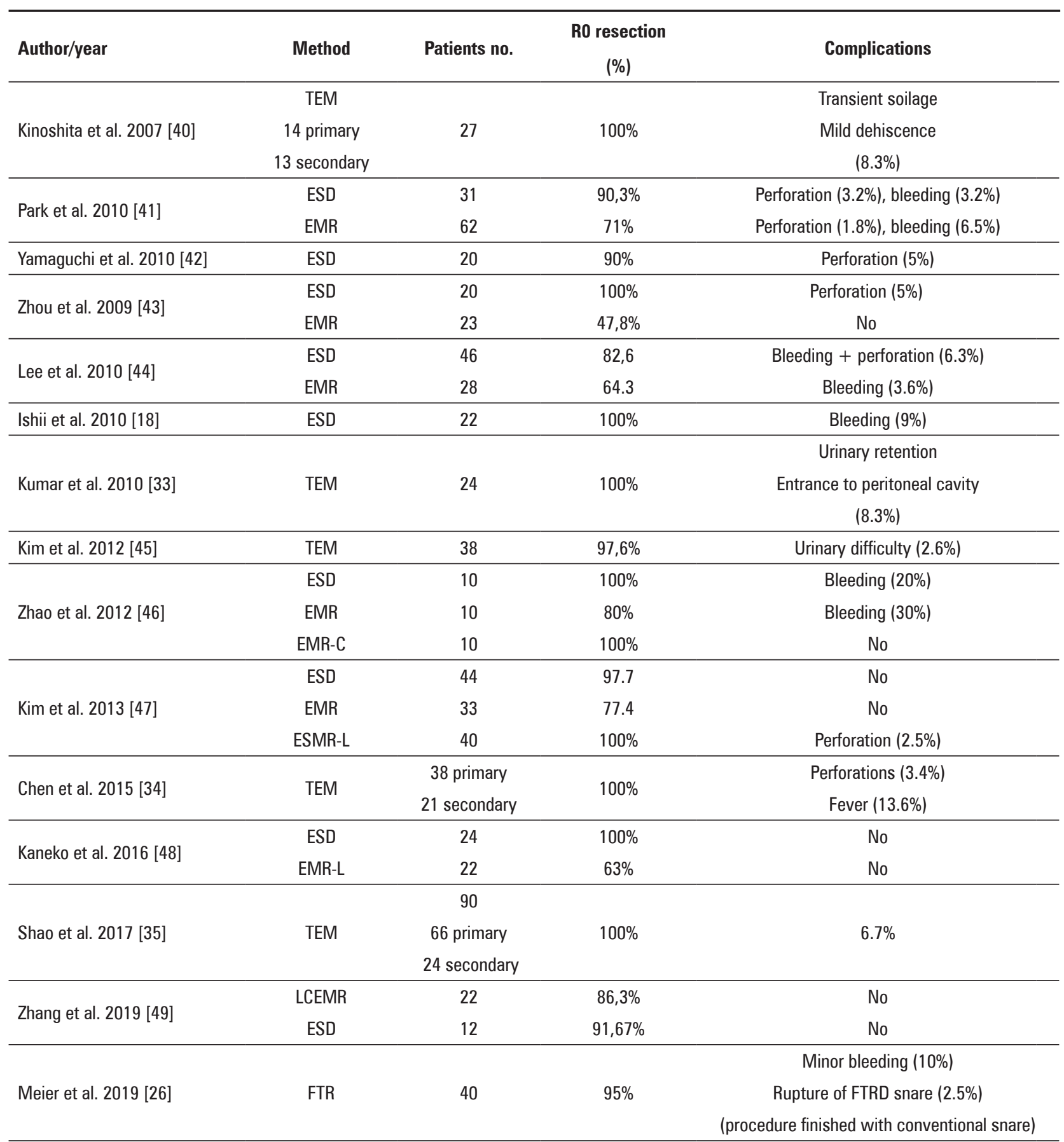

EMR-C — cap assisted endoscopic mucosal resection; ESMR-L — endoscopic submucosal resection with a ligation device; LCEMR — endoloop ligation after cap-endoscopic mucosal resection; FTR — full-thickness resection; FTRD — full-thickness resection device

and long-term observations describing disease recurrence after polypectomy [8]. However, the evidence supporting this management is not very strong due to the lack of large comparative studies comparing the outcomes of patients after non-curative endoscopic resection who did not undergo adjunct therapy and those who underwent salvage treatment.

Cha et al. followed up a group of 322 patients who underwent endoscopic resection of rNENs and found that only $31 \%$ (44/142) of the patients who did not fulfil the criteria of $\mathrm{R} 0$ resection underwent salvage therapy [11]. Eleven of these patients underwent surgery, and lymph node metastases were found in six patients, while there were no features of disease progression in the remaining patients [11]. The study by Fine et al. in patients with rNENs showed a generally favourable natural history, and recurrence after endoscopic resection was only observed in $5 \%$ of cases $(16 / 345)$ in the 
median follow-up of 32 months; however, in two cases it led to patient death [10]. This study also revealed that the neuroendocrine origin of the polyps is suspected in a minority of cases on endoscopy, before the polypectomy is conducted, and even when the diagnosis is suspected, many of rNEN are removed with a snare polypectomy, justifying the continuous education of endoscopists in this field [10]. This conclusion is in accordance with the results of our study, which showed that endoscopists suspected polyps of neuroendocrine origin in only $37.5 \%$ of cases (9/24 lesions) [9].

In studies analysing the pathological results of salvage therapies, the presence of remnant tumour in resected scars was reported in a significant number of cases (4/27 in the study by Kumar et al. [33], 9/21 in the study by Chen et al. [34], 10/24 in the study by Shao et al. [35], and in 7/31 cases in the study by Pagano N et al. [36]). In the study by Pagano et al. the authors stated that the only independent factor related to residual disease (present in $22.6 \%$ of patients treated with ESD as salvage therapy) was the size of the polyps, and they showed that ESD was indicated in lesions larger than $3 \mathrm{~mm}(60-90 \%$ probability of residual disease) [36].

In a previous study, the authors performing TEM as salvage therapy recommended tattooing the scar with an ink before the procedure because they postulated that it leads to better visualisation, facilitates FTR, and results in a higher percentage of curative resections [33]. The disadvantage of scar marking is that it can lead to fibrosis and make adjunct endoscopic treatment more difficult. The decision on which method (ESD/TEM) should be used as optimal for salvage therapy in patients who do not meet the criteria for surgery should be made individually, taking into account the same factors as those noted for primary treatment.

\section{Summary and Conclusions}

The compliance with guidelines is poor, justifying the education of physicians, particularly endoscopists, dealing with rNENs, in terms of primary treatment and salvage therapy after polypectomy. The polypectomy of rectal NETs results in unacceptably high non-curative resection rates. The diagnosis of typical submucosal lesion should be made on endoscopy, and patients should be referred for more advanced treatment (EMR/ESD/TEM), preceded by EUS. An endoscopic mucosal resection should be reserved for small $(<10 \mathrm{~mm})$ rectal NENs, and when possible, modified methods of EMR should be applied.

ESD and TEM are optimal methods for the treatment of rectal NENs that do not qualify for surgery, both of which can be used as primary treatment and salvage therapy. Comparative studies and meta-analysis are needed to determine which method is optimal for treatment in primary and secondary settings.

$\mathrm{R} 0$ resection rates, complications, patient preference, and experience of the centre are factors that should be taken into account when making decisions about therapy.

Taking into account the feasibility, safety, and effectiveness FTR seems to be a promising alternative to the aforementioned methods in terms of both primary and salvage therapy for rNENs.

\section{Disclosure}

The authors declare no conflict of interest.

\section{References}

1. Starzyńska T, Londzin-Olesik M, Bałdys-Waligórska A, et al. Colorectal neuroendocrine neoplasms - management guidelines (recommended by the Polish Network of Neuroendocrine Tumours). Endokrynol Pol. 2017; 68(2): 250-260, doi: 10.5603/EP.2017.0019, indexed in Pubmed: 28540975.

2. Chablaney S, Zator Z, Kumta N. Diagnosis and Management of Rectal Neuroendocrine Tumors. Clin Endoscop. 2017; 50(6): 530-536, doi: 10.5946/ce.2017.134.

3. de Mestier L, Brixi H, Gincul R, et al. Updating the management of patients with rectal neuroendocrine tumors. Endoscopy. 2013; 45(12): 1039-1046, doi: 10.1055/s-0033-1344794, indexed in Pubmed: 24163193.

4. Caplin M, Sundin A, Nillson O, et al. Barcelona Consensus Conference participants. ENETS Consensus Guidelines for the management of patients with digestive neuroendocrine neoplasms: colorectal neuroendocrine neoplasms. Neuroendocrinology. 2012; 95(2): 88-97, doi: 10.1159/000335594, indexed in Pubmed: 22261972.

5. Ramage JK, De Herder WW, Delle Fave G, et al. Vienna Consensus Conference participants. ENETS Consensus Guidelines Update for Colorectal Neuroendocrine Neoplasms. Neuroendocrinology. 2016; 103(2): 139-143, doi: 10.1159/000443166, indexed in Pubmed: 26730835.

6. Onozato $\mathrm{Y}$, Kakizaki S, Iizuka H, et al. Endoscopic treatment of rectal carcinoid tumors. Dis Colon Rectum. 2010; 53(2): 169-176, doi: 10.1007/DCR.0b013e3181b9db7b, indexed in Pubmed: 20087092.

7. Son HJ, Sohn DK, Hong CW, et al. Factors associated with complete local excision of small rectal carcinoid tumor. Int J Colorectal Dis. 2013; 28(1): 57-61, doi: 10.1007/s00384-012-1538-z, indexed in Pubmed: 22821140.

8. Judd S, Nangia S, Levi E, et al. Rectal carcinoid tumor: a delayed localized recurrence 23 years after endoscopic resection. Endoscopy. 2014; 46 Suppl 1 UCTN: E555-E556, doi: 10.1055/s-0034-1377950, indexed in Pubmed: 25409070.

9. Dabkowski K, Białek A, Rusiniak-Rossińska N, et al. Endoscopic treatment of rectal neuroendocrine tumors in a 12 year retrospective single center study. ESGE Days 2019. 2019, doi: 10.1055/s-0039-1681572.

10. Fine C, Roquin G, Terrebonne E, et al. Endoscopic management of 345 small rectal neuroendocrine tumours: A national study from the French group of endocrine tumours (GTE). United European Gastroenterol J. 2019; 7(8): 1102-1112, doi: 10.1177/2050640619861883, indexed in Pubmed: 31662867.

11. Cha JH, Jung DaH, Kim JH, et al. Long-term outcomes according to additional treatments after endoscopic resection for rectal small neuroendocrine tumors. Sci Rep. 2019; 9(1): 4911, doi: 10.1038/s41598-019-40668-6, indexed in Pubmed: 30894571.

12. Lee SP, Sung IK, Kim JH, et al. The effect of preceding biopsy on complete endoscopic resection in rectal carcinoid tumor. J Korean Med Sci. 2014; 29(4): 512-518, doi: 10.3346/jkms.2014.29.4.512, indexed in Pubmed: 24753698.

13. Kudo S, Hirota S, Nakajima T, et al. Colorectal tumours and pit pattern. J Clin Pathol. 1994; 47(10): 880-885, doi: 10.1136/jcp.47.10.880, indexed in Pubmed: 7962600.

14. McGill SK, Evangelou E, Ioannidis JPA, et al. Narrow band imaging to differentiate neoplastic and non-neoplastic colorectal polyps in real time: a meta-analysis of diagnostic operating characteristics. Gut 2013; 62(12): 1704-1713, doi: 10.1136/gutjnl-2012-303965, indexed in Pubmed: 23300139.

15. Lahner E, Esposito G, Angeletti S, et al. Endoscopic appearances of polypoid type 1 gastric microcarcinoids by narrow-band imaging: a case series in a referral center. Eur J Gastroenterol Hepatol. 2016; 28(4): 463-468, doi: 10.1097/MEG.0000000000000566, indexed in Pubmed: 26745471. 
16. Lin CK, Chung CS, Huang WC. Rectal carcinoid tumour observed by magnifying colonoscopy with narrow band imaging. Dig Liver Dis. 2014 46(7): e7, doi: 10.1016/j.dld.2013.12.003, indexed in Pubmed: 24411486.

17. Kobayashi K, Katsumata T, Yoshizawa S, et al. Indications of endoscopic polypectomy for rectal carcinoid tumors and clinical usefulness of endoscopic ultrasonography. Dis Colon Rectum. 2005; 48(2): 285-291, doi: 10.1007/s10350-004-0765-y, indexed in Pubmed: 15714250.

18. Ishii N, Horiki N, Itoh T, et al. Endoscopic submucosal dissection and preoperative assessment with endoscopic ultrasonography for the treatment of rectal carcinoid tumors. Surg Endosc. 2010; 24(6): 1413-1419, doi: 10.1007/s00464-009-0791-x, indexed in Pubmed: 20033710

19. Park SuB, Kim DJ, Kim HW, et al. Is endoscopic ultrasonography essential for endoscopic resection of small rectal neuroendocrine tumors? World J Gastroenterol. 2017; 23(11): 2037-2043, doi: 10.3748/wjg.v23.i11.2037, indexed in Pubmed: 28373770.

20. Onozato Y, Kakizaki S, Iizuka H, et al. Endoscopic treatment of rectal carcinoid tumors. Dis Colon Rectum. 2010; 53(2): 169-176, doi: 10.1007/DCR.0b013e3181b9db7b, indexed in Pubmed: 20087092

21. Kim JH, Moon W, Park SJa, et al. Clinical impact of endoscopic ultrasonography for small rectal neuroendocrine tumors. Turk J Gastroenterol. 2014; 25(6): 657-660, doi: 10.5152/tjg.2014.6647, indexed in Pubmed: 25599777.

22. Kwak MS, Chung SuJ, Yang JIn, et al. Long-term Outcome of Small, Incidentally Detected Rectal Neuroendocrine Tumors Removed by Simple Excisional Biopsy Compared With the Advanced Endoscopic Resection During Screening Colonoscopy. Dis Colon Rectum. 2018; 61(3): 338-346, doi: 10.1097/DCR.0000000000000905, indexed in Pubmed: 29369898

23. Gleeson FC, Levy MJ, Dozois EJ, et al. Endoscopically identified well-differentiated rectal carcinoid tumors: impact of tumor size on the natural history and outcomes. Gastrointest Endosc. 2014; 80(1): 144-151, doi: 10.1016/j.gie.2013.11.031, indexed in Pubmed: 24462168.

24. Zhou X, Xie H, Xie L, et al. Endoscopic resection therapies for rectal neuroendocrine tumors: a systematic review and meta-analysis. J Gastroenterol Hepatol. 2014; 29(2): 259-268, doi: 10.1111/jgh.12395, indexed in Pubmed: 24118068.

25. Saclarides TJ, Smith L, Ko ST, et al. Transanal endoscopic microsurgery. Dis Colon Rectum. 1992; 35(12): 1183-1191, doi: 10.1007/BF02251975, indexed in Pubmed: 1473424

26. Meier B, Albrecht H, Wiedbrauck T, et al. Full-thickness resection of neuroendocrine tumors in the rectum. Endoscopy. 2020; 52(1): 68-72, doi: 10.1055/a-1008-9077, indexed in Pubmed: 31614372.

27. Schmidt A, Bauerfeind P, Gubler C, et al. Endoscopic full-thickness resection in the colorectum with a novel over-the-scope device: firs experience. Endoscopy. 2015; 47(8): 719-725, doi: 10.1055/s-0034-1391781, indexed in Pubmed: 25763833.

28. Grauer M, Gschwendtner A, Schäfer C, et al. Resection of rectal carcinoids with the newly introduced endoscopic full-thickness resection device. Endoscopy. 2016; 48 Suppl 1: E123-E124, doi: 10.1055/s-0042-104651, indexed in Pubmed: 27008564.

29. Klare P, Burlefinger R, Neu B, et al. Over-the-scope clip-assisted endoscopic full-thickness resection after incomplete resection of a recta neuroendocrine tumor. Endoscopy. 2015; 47 Suppl 1 UCTN: E47-E48, doi: 10.1055/s-0034-1391301, indexed in Pubmed: 25643136.

30. Tashima T, Nonaka K, Ryozawa S. Successful endoscopic en bloc full-thickness and complete resection for two adjacent rectal neuroendocrine tumors. Dig Endosc. 2019; 31(5): 592, doi: 10.1111/den.13455, indexed in Pubmed: 31166630.

31. Kwaan MR, Goldberg JE, Bleday R. Rectal carcinoid tumors: review of results after endoscopic and surgical therapy. Arch Surg. 2008; 143(5): 471-475, doi: 10.1001/archsurg.143.5.471, indexed in Pubmed: 18490556

32. Maeda K, Maruta M, Utsumi T, et al. Minimally invasive surgery for carcinoid tumors in the rectum. Biomed Pharmacother . 2002 56(Suppl 1): 222s-226s, doi: 10.1016/s0753-3322(02)00218-4, indexed in Pubmed: 12487287.

33. Kumar AS, Sidani SM, Kolli K, et al. Transanal endoscopic microsurgery for rectal carcinoids: the largest reported United States experience.
Colorectal Dis. 2012; 14(5): 562-566, doi: 10.1111/j.1463-1318.2011.0272 6.x, indexed in Pubmed: 21831099.

34. Chen WJ, Wu N, Zhou JL, et al. Full-thickness excision using transanal endoscopic microsurgery for treatment of rectal neuroendocrine tumors. World J Gastroenterol. 2015; 21(30): 9142-9149, doi: 10.3748/wjg. v21.i30.9142, indexed in Pubmed: 26290641.

35. Shao $\mathrm{Q}$, Lin $\mathrm{G}$, Qiu $\mathrm{H}$. Transanal endoscopic microsurgery for treatment of rectal neuroendocrine tumors. Zhonghua Wei Chang Wai Ke Za Zhi. 2017; 20 (29): 1009-1014, doi: 10.3748/wjg.v21.i30.9142, indexed in Pubmed: 26290641

36. Pagano N, Ricci C, Brighi N, et al. Incidental diagnosis of very small rectal neuroendocrine neoplasms: when should endoscopic submucosa dissection be performed? A single ENETS centre experience. Endocrine. 2019; 65(1): 207-212, doi: 10.1007/s12020-019-01907-y, indexed in Pubmed: 30919286.

37. Shah MH, Goldner WS, Halfdanarson TR, et al. NCCN Guidelines Insights: Neuroendocrine and Adrenal Tumors, Version 2.2018. J Nat Compr Canc Netw. 2018; 16(6): 693-702, doi: 10.6004/jnccn.2018.0056, indexed in Pubmed: 29891520.

38. Anthony LB, Strosberg JR, Klimstra DS, et al. North American Neuroendocrine Tumor Society (NANETS). The NANETS consensus guidelines for the diagnosis and management of gastrointestinal neuroendocrine tumors (nets): well-differentiated nets of the distal colon and rectum. Pancreas. 2010; 39(6): 767-774, doi: 10.1097/MPA.0b013e3181ec1261, indexed in Pubmed: 20664474

39. Amin MB, Edge S. AJCC cancer staging manual. 8th ed. Springer, New York 2016.

40. Kinoshita T, Kanehira E, Omura K, et al. Transanal endoscopic microsurgery in the treatment of rectal carcinoid tumor. Surg Endosc. 2007; 21(6): 970-974, doi: 10.1007/s00464-006-9155-y, indexed in Pubmed: 17285371

41. Park HW, Byeon JS, Park YS, et al. Endoscopic submucosal dissection for treatment of rectal carcinoid tumors. Gastrointest Endosc. 2010; 72(1): 143-149, doi: 10.1016/j.gie.2010.01.040, indexed in Pubmed: 20381798.

42. Yamaguchi N, Isomoto $\mathrm{H}$, Nishiyama $\mathrm{H}$, et al. Endoscopic submucosal dissection for rectal carcinoid tumors. Surg Endosc. 2010; 24(3): 504-508, doi: 10.1007/s00464-009-0606-0, indexed in Pubmed: 19585069.

43. Zhou PH, Yao LQ, Qin XY, et al. Advantages of endoscopic submucosal dissection with needle-knife over endoscopic mucosal resection for small rectal carcinoid tumors: a retrospective study. Surg Endosc. 2010; 24(10): 2607-2612, doi: 10.1007/s00464-010-1016-Z, indexed in Pubmed: 20361212.

44. Lee DS, Jeon SW, Park SY, et al. The feasibility of endoscopic submucosal dissection for rectal carcinoid tumors: comparison with endoscopic mucosal resection. Endoscopy. 2010; 42(8): 647-651, doi: 10.1055/s-0030-1255591, indexed in Pubmed: 20669076.

45. Kim HR, Lee WY, Jung KUk, et al. Transanal endoscopic microsurgery for the treatment of well-differentiated rectal neuroendocrine tumors. J Korean Soc Coloproctol. 2012; 28(4): 201-204, doi: 10.3393/jksc.2012.28.4.201, indexed in Pubmed: 22993706.

46. Zhao ZF, Zhang N, Ma SR, et al. A comparative study on endoscopy treatment in rectal carcinoid tumors. Surg Laparosc Endosc Percutan Tech. 2012; 22(3): 260-263, doi: 10.1097/SLE.0b013e3182512e0f, indexed in Pubmed: 22678324

47. Kim KM, Eo SJ, Shim SG, et al. Treatment outcomes according to endoscopic treatment modalities for rectal carcinoid tumors. Clin Res Hepato Gastroenterol. 2013; 37(3): 275-282, doi: 10.1016/j.clinre.2012.07.007, indexed in Pubmed: 22959100.

48. Kaneko H, Hirasawa K, Koh R, et al. Treatment outcomes of endoscopic resection for rectal carcinoid tumors: an analysis of the resectability and long-term results from 46 consecutive cases. Scand J Gastroenterol. 2016; 51(12): 1489-1494, doi: 10.1080/00365521.2016.1216591, indexed in Pubmed: 27687741.

49. Zhang DG, Luo Su, Xiong F, et al. Endoloop ligation after endoscopic mucosal resection using a transparent cap: A novel method to treat small rectal carcinoid tumors. World J Gastroenterol. 2019; 25(10): 1259-1265, doi: 10.3748/wjg.v25.i10.1259, indexed in Pubmed: 30886508. 